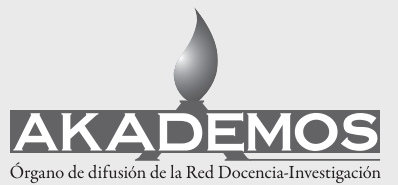

ISSN: 1995-4743

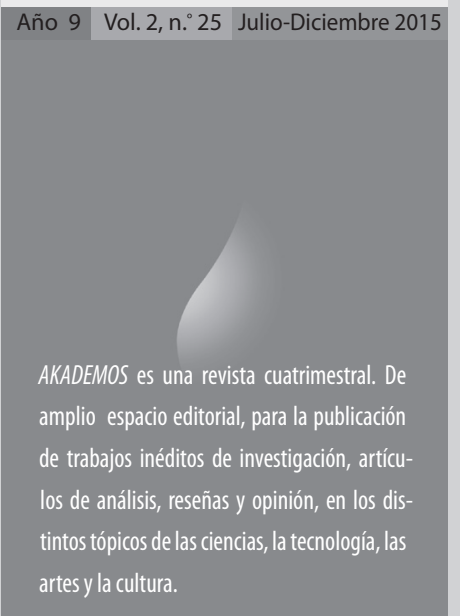

San Salvador, El Salvador, Centroamérica

\title{
Declaración y pago de cotizaciones previsionales*
}

\section{Francisco Sorto Rivas}

Máster en Economía, Docente investigador,

Facultad de Posgrados y Educación Continua.

fran.sorto@gmail.com

\section{Resumen}

Este trabajo se refiere al pago de las cotizaciones previsionales en los sistemas de pensiones contributivos y las acciones de cobro emprendidas por las gestoras del sistema, ante el incumplimiento de estos compromisos por parte de algunos empleadores.

Para ilustrar este documento se utilizó, de referencia, la experiencia salvadoreña del SAP, el SPP y del IPSFA, aprovechando que este último está promoviendo una serie de reformas paramétricas y estructurales a su Ley de creación. Asimismo, se utilizó la realidad chilena, en la misma materia, con propósitos comparativos.

De igual manera se mencionan algunas acciones que podrían fortalecer el cumplimiento de las obligaciones previsionales en El Salvador o, al menos, ampliar la protección de los trabajadores ante el incumpli-

Agradezco la autorización del Coronel y Lic. René Díaz Argueta, Gerente General del IPSFA, para usar información de esa Institución en este trabajo; a AFP Confía por facilitarme algunos de sus formularios de recaudación y afiliación; así como a la señora Cristina Villalobos por su apoyo secretarial 
miento del pago de las cotizaciones previsionales por parte de sus empleadores.

El propósito principal de este artículo, en todo caso, es describir aspectos esenciales de los sistemas de pensiones contributivos, principalmente, aquellos basados en la capitalización individual y, más concretamente, cómo funcionan estos regímenes, en El Salvador, en cuanto a la recaudación de cotizaciones previsionales se refiere.

Palabras Clave: Cobro Administrativo y Judicial, Declaración y Pago de Cotizaciones, Planillas Previsionales, Mora Presunta, Mora Previsional, Sistemas de Generación de Planillas.

\section{Desarrollo}

Cuando los trabajadores ya se han incorporado a algún sistema de protección social de carácter contributivo, es decir que, los partícipes aportan al financiamiento de las prestaciones otorgadas a sus miembros cuando se jubilan o salen del sistema, tras configurarse algunas de las condiciones establecidas por el legislador para tales efectos (invalidez, cesantía en edad avanzada, etc.) ${ }^{1}$, los afiliados deben hacer llegar sus aportes regularmente -todos los meses- a la entidad gestora del sistema a que pertenezcan.

En algunas ocasiones estos aportes pueden enterarse directamente en las entidades gestoras, para lo cual estas últimas disponen de cajas habilitadas para la recepción de esos pagos; en otras oportunidades, las contribu- ciones se efectúan a través del sistema bancario, tal como sucede en El Salvador.

Tanto en el caso del IPSFA como de las gestoras privadas de fondos de retiro, en El Salvador (AFP), el pago de las cotizaciones previsionales se hace mediante el sistema bancario, utilizando para ello planillas físicas o formatos electrónicos, ya sea almacenando datos en algún medio físico o mediante la transferencia directa de archivos de texto.

Conforme ha pasado el tiempo y la experiencia en esta materia lo ha sugerido, se han diseñado software para la elaboración de las planillas en mención.

En el gráfico siguiente se representa cómo procede la generación de una planilla y el envío de los recursos del empleador -en la esquina superior izquierda- a través del sistema bancario, hacia las instituciones administradoras de regímenes previsionales (IPSFA y AFP) -en el extremo derecho del gráfico-; estas cotizaciones se invierten luego como reservas técnicas, en el caso del primero y forman parte del portafolio de inversiones de los Fondos de Pensiones, en el caso de las últimas.

1 Debido al destino específico que tienen los recursos acumulados en los sistemas de seguridad social, sólo se pueden utilizar cuando se configuran las causales establecidas en la Ley que los regula. 


\section{Gráfico 1}

DECLARACIÓN Y PAGO DE COTIZACIONES

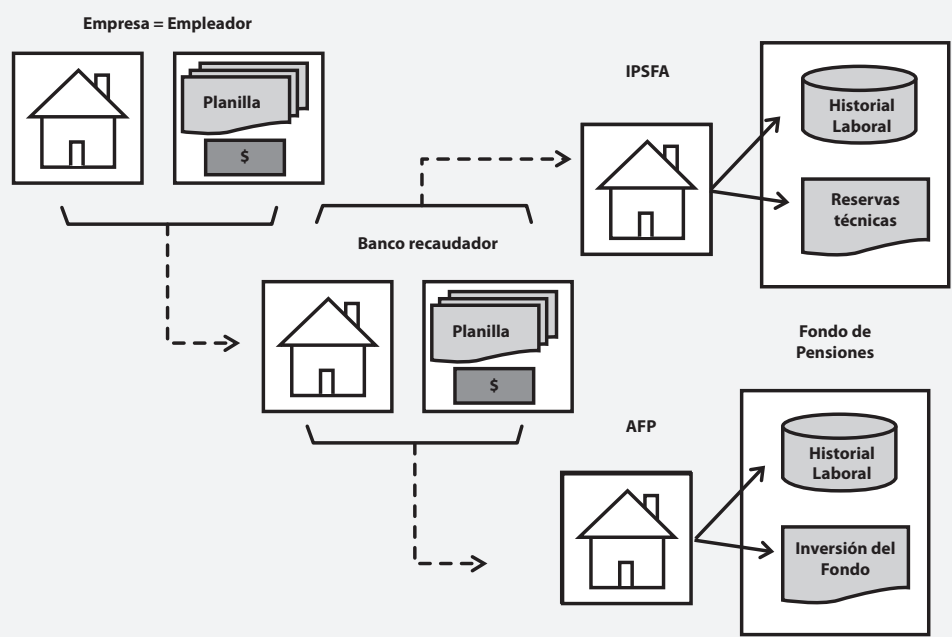

Fuente: Elaboración propia

Por otro lado, en la normativa emitida para regular esta actividad, puede preverse que el empleador retenga la cotización correspondiente al trabajador y la envíe a la institución donde se encuentre afiliado y que, además, remitan su aporte como carga social, utilizando para ello el mismo medio; éste puede ser una planilla de pago que contenga información suficiente para identificar a quién pertenecen las contribuciones, por ejemplo.

La presentación de esta planilla constituye, en sí mismo, un reconocimiento de la deuda que tiene el empleador con el afiliado, cuando el sistema es de Capitalización Individual, por un lado; y con la institución que administra el régimen, cuando nos referimos a sistemas de reparto, por el otro.
En ambos casos, el empleador tiene una obligación de pago, pero dependiendo del tipo de sistema analizado, el acreedor será distinto; éste sería el trabajador (sistema de capitalización individual) o la entidad gestora (sistema de reparto); aunque cuando se trata de un sistema de capitalización, el afiliado ejerce su derecho a cobrar las cotizaciones y aportes previsionales, a través de la entidad gestora donde se encuentra afiliado.

Dicha entidad, en representación del trabajador, reclama el pago de las cotizaciones cuando -por alguna razón- el empleador no las ha cancelado oportunamente, generándose así una condición de mora. 
La Ley prescribe, normalmente, un plazo para la presentación y pago de las cotizaciones previsionales; en el caso del IPSFA que administra regímenes bajo la modalidad de reparto, recibe estas cotizaciones de la población que se incorporó al Instituto, al amparo del Decreto Legislativo No. 727, en los primeros 10 días hábiles del mes; mientras que los pagos provenientes del Ministerio de la Defensa Nacional se reciben, normalmente, en la tercera semana del mes.
Cada régimen tiene su propia regla en materia de plazos para la presentación y pago de las cotizaciones previsionales; en el SAP, la norma establece que las cotizaciones se deberán pagar durante los primeros 10 días hábiles del mes y la SSF publica un calendario de días, no hábiles, para que el sistema bancario conozca cuáles son las fechas límites de recepción de contribuciones, tal como aparece en el Recuadro 1, donde se recoge lo dispuesto sobre esta materia en el SAP.

\section{Recuadro 1}

Art. 19.- Las cotizaciones establecidas en este Capítulo deberán ser declaradas y pagadas por el empleador, el trabajador independiente o la entidad pagadora de subsidios de incapacidad por enfermedad, según corresponda, en la Institución Administradora en que se encuentre afiliado cada trabajador.

Para este efecto, el empleador descontará del ingreso base de cotización de cada afiliado, al momento de su pago, el monto de las cotizaciones a que se refiere el artículo 16 de esta Ley y el de las voluntarias que expresamente haya autorizado cada afiliado, y trasladará estas sumas, junto con la correspondiente a su aporte, a las Instituciones Administradoras respectivas.

La declaración y pago deberán efectuarse dentro de los diez primeros días hábiles del mes siguiente a aquél en que se devengaron los ingresos afectos, o a aquél en que se autorizó la licencia médica por la entidad correspondiente, en su caso...

Agotado el plazo de presentación normal de las planillas previsionales en el sistema bancario, éstas se consideran en mora y los pagos sólo pueden ser recibidos, en el banco, previo cálculo de recargos realizados en las AFP, a solicitud del empleador; con estas órdenes de pagos emitidas por las AFP -con fecha de caducidad, por supuesto-, el banco queda habilitado para recibir los pagos con posterioridad a la fecha límite establecida por la Ley.

Claro que estos pagos tienen un recargo, tanto en el caso del IPSFA como en 
el SAP; no obstante, la naturaleza del recargo difiere, ya que en el IPSFA se considera parte de los ingresos financieros del Instituto; mientras que en el SAP incluye la rentabilidad dejada de percibir por los trabajadores debido al pago inoportuno de sus cotizaciones.

Regresando al tema de la declaración y pago de las cotizaciones previsionales, merece la pena señalar que, en algunos casos, se admite que estas acciones se realicen de forma separada, de tal manera que el empleador presente en un primer momento la declaración de cotizaciones, para efectos del reconocimiento de la obligación, sin cancelarla inmediatamente.

Así sucede en el caso salvadoreño con el SAP, supuestamente para disponer de un documento que sirva de prueba para reclamar mora, cuando los pagos no se realizan como se esperaba.

Esta figura se incorporó en la normativa nacional a partir de la experiencia chilena, donde la realidad jurídica es distinta a la local, ya que, con este documento podría iniciarse un juicio en los tribunales competentes para recuperar las cotizaciones pendientes a favor de los trabajadores.

Sin embargo, en el país este reconocimiento no es suficiente para iniciar una acción jurídica en contra de empleadores morosos; la norma salvadoreña agregó una figura exprofeso para iniciar estas acciones, la cual requiere, por cierto, de la aceptación por parte del empleador de la condición de mora.
En caso que él no colabore en la admisión de la deuda, el documento base de la acción que pormenoriza las obligaciones pendientes, no es admitido para iniciar con él un juicio mercantil.

Es tal la desnaturalización en que ha caído el cobro judicial de la mora previsional en este país que, cuando la Fiscalía General de la República (FGR) -a requerimiento de los afectados-, pretende iniciar una acción judicial, al amparo del artículo 245 del Código Penal ${ }^{2}$, donde se considera como delito la apropiación indebida de las cotizaciones previsionales, ha promovido conciliaciones entre las partes (trabajadores y empleadores).

Como resultado de dichas iniciativas, los empleadores han conciliado directamente con los trabajadores, afectándose con ello su historial laboral (HL) y el proceso de acumulación de fondos en sus cuentas individuales porque el dinero no entró en su CIAP, ni engrosó su HL; de igual manera, con este tipo de arreglos imperfectos se ven afectadas las acciones emprendidas por las

2 El Código Penal en su Art. 245 señala lo siguiente: El patrono, empleador, pagador institucional, o cualquier otra persona responsable de la retención, que se apropiare o que retuviere ilegalmente fondos, contribuciones, cotizaciones, cuotas de amortización de préstamos de los trabajadores 0 cuentas destinadas legalmente al Estado, instituciones de crédito o bancarias, intermediarios financieros bancarios o no bancarios, 0 instituciones de asistencia social, seguridad social o sindical; 0 no los ingrese en tales instituciones en el plazo y monto determinado en la ley, en el contrato correspondiente 0 en la orden de descuento, será sancionado con prisión de cuatro a ocho años.

Para la fijación de la sanción, el juez tomará en cuenta el número de cuotas retenidas y la cuantía de las mismas... 
gestoras de fondos, en procura de los intereses de sus afiliados, para recuperar las cotizaciones pendientes; esto es así porque los empleadores presentan finiquitos obtenidos así, en casos ventilados en los tribunales de lo mercantil, a raíz de las mismas deudas previsionales conciliadas u otras.

La FGR actúa así probablemente por la carga de trabajo que tiene cada fiscal, o por el desconocimiento de la ley vigente en materia de seguridad social, comenzando por los artículos 50, 51 y 52 de la ley primaria de la República, donde se establece que los derechos a la seguridad social son irrenunciables, por lo que, una conciliación en esta materia carecería de validez jurídica, aun cuando en dicho proceso haya intervenido el ministerio público. (Ver Recuadro 2)

\section{Recuadro 2}

Art. 50.- La seguridad social constituye un servicio público de carácter obligatorio. La ley regulará sus alcances, extensión y forma.

Dicho servicio será prestado por una o varias instituciones, las que deberán guardar entre sí la adecuada coordinación para asegurar una buena política de protección social, en forma especializada y con óptima utilización de los recursos.

Al pago de la seguridad social contribuirán los patronos, los trabajadores y el Estado en la forma y cuantía que determine la ley.

El Estado y los patronos quedarán excluidos de las obligaciones que les imponen las leyes en favor de los trabajadores, en la medida en que sean cubiertas por el Seguro Social.

Art. 51.- La ley determinará las empresas y establecimientos que, por sus condiciones especiales, quedan obligados a proporcionar, al trabajador y a su familia, habitaciones adecuadas, escuelas, asistencia médica y demás servicios y atenciones necesarios para su bienestar.

Art. 52.- Los derechos consagrados en favor de los trabajadores son irrenunciables.

La enumeración de los derechos y beneficios a que este capítulo se refiere, no excluye otros que se deriven de los principios de justicia social. 
De igual manera, existe una discusión permanente sobre el tema de la mora previsional y las acciones emprendidas para recuperarla, tanto a nivel administrativo como jurisdiccional; abarcando en este último caso, el ámbito mercantil y penal.

Esto último surge debido a que el pago inoportuno, insuficiente o la omisión total de la declaración y pago de las cotizaciones previsionales están sujetos al pago de una multa administrativa, es decir, se considera como una falta, no como un delito.

Por otro lado, debido a lo permisivo que resultaba ese tratamiento para la práctica interna de incumplimiento de la normativa de seguridad social, el legislador consideró oportuno elevar al rango de delito no excarcelable la apropiación indebida de las cotizaciones previsionales, es decir que, este delito puede sancionarse con sentencias que oscilan entre los cuatro y ocho años de prisión, dependiendo de la frecuencia y cuantía de la apropiación.

De igual manera, después de agotado el período para el cobro administrativo de las cotizaciones previsionales, la Ley del SAP contempla, en su artículo 20, que la cobranza judicial debe incoarse ante un tribunal de lo mercantil o de menor cuantía, según los montos adeudados.

Todo esto genera conflictos a la hora de aplicar el principio de doble juzgamiento. ${ }^{3}$ Tal situación se deriva del hecho que la normativa dispersa contempla sanciones propias, provenientes de una causa aparen- temente común; refiriéndonos en este caso al incumplimiento de pago de las cotizaciones previsionales, siendo el carácter punitivo distinto en cada norma; en unos casos se pretende sancionar la comisión de un delito; en otros, la infracción de una norma y por el otro, se busca restablecer el estado en que se encontraría la cuenta de un afiliado, de no haberse presentado la mora.

Según se desprende de lo antes señalado, el delito se origina por la retención de las cuotas previsionales a cargo del trabajador, por parte de su empleador, sin que éste las reporte y pague a la AFP, apropiándose así del dinero de los trabajadores. Esto es un delito.

Por otra parte, la Ley del SAP obliga al empleador a efectuar aportaciones a la seguridad social, a fin de liberarse de la responsabilidad pecuniaria de otorgarles beneficios como los contemplados en la Ley, en caso de presentarse alguna de las causales en el SAP para obtener algún beneficio; atendiendo lo dispuesto en el artículo 50 de la Constitución de la República.

3 El derecho penal moderno se erige sobre una serie de principios diseñados con el propósito de garantizar al acusado las más amplias oportunidades de defensa frente al ejercicio -en muchas ocasiones abusivo- del ius puniendi estatal. Entre tales principios uno de los más importantes es la prohibición del doble juzgamiento, conocido universalmente como ne bis in idem o non bis in idem, que impide al Estado someter a una persona a procesamientos consecutivos por un mismo delito, bajo el argumento de haber fracasado en su primer intento de hacer justicia, con la consecuente afectación psicológica, moral y en ocasiones física que ello conlleva. 
Además, el sentido teleológico de las sanciones consiste en disuadir el incumplimiento de pago de las obligaciones a favor de los trabajadores; de ahí que, la norma contemple el restablecimiento de las condiciones que tendría la cuenta del afiliado, de no haberse suscitado el incumplimiento en el pago de las cotizaciones, por lo que, la normativa vigente requiere que el empleador reconozca, al afiliado, la rentabilidad dejada de percibir por el pago inoportuno de los referidos aportes.

El principal problema que se origina ante la diversidad de propósitos normativos, provienen del conflicto doctrinario, ya que se supondría que en caso de acumularse procesos que pudieran tener naturaleza similar, debería sancionarse al infractor con la mayor de las penas que pudieran aplicársele; a manera de ejemplo, el caso de un secuestro, violación y asesinato posterior de la víctima; si bien es cierto que podrían contemplarse sentencias secuenciales y no concurrentes, la lógica nos indica que, la condena debería ser aquella que sancionara el delito más grave.

Esto explica, probablemente, que algunos abogados consideren que enviar a la cárcel a un moroso sería suficiente para la extinción del resto de reclamaciones; sin embargo, esto no sería así, ya que el restablecimiento del saldo de la cuenta del trabajador debería privilegiarse por ser la parte agraviada de donde se originan las demás acciones, incluyendo, aquellas ventiladas en el ámbito penal.
El tratamiento en sí de la cobranza judicial -de las obligaciones previsionales-, desencadenan una diversidad de situaciones, ya que, por iniciarse las AFP estas reclamaciones -en los tribunales de lo mercantil o de menor cuantía-, algunos jueces creen que la demanda obedece a intereses propios de la gestora y no, que ésta está actuando en representación de trabajadores afectados.

Muchas veces se confunden estas acciones emprendidas por las administradoras, con el resto de demandas promovidas por instituciones del sistema financiero, como bancos y compañías de seguros.

En ese sentido, se generan anticuerpos en el proceso. Al confundirse la pretensión de pago, con una motivación patrimonial propia de la administradora, no se le da la celeridad debida en los tribunales y, en más de una ocasión ha sucedido que, por la tardanza en la administración de justicia, se resuelven demandas cuando algunos trabajadores ya han fallecido y las reclamaciones de pensiones, por parte de sus beneficiarios, han sufrido contratiempos considerables.

Ante las dificultades que entraña la cobranza judicial de la mora previsional, suelen crearse mecanismos expeditos de control y recuperación administrativa, con el apoyo de las entidades rectoras de los sistemas previsionales. Asimismo, cuando la gestión de los regímenes de seguridad social recae en entidades estatales, se abren oficinas para que se encarguen de esta recuperación; las cuales gozan de cierta libertad 
para conciliar la mayoría de controversias sobre la problemática.

En el caso del IPSFA, también tiene un departamento encargado de la recuperación de la mora previsional asociada con la población reafiliada al amparo del decreto 727 , ya que en caso de los afiliados de la Fuerza Armada, este tipo de eventos no ocurren y cuando suceden, obedecen a deficiencias en la información suministrada a la Institución y se puede depurar con bastante facilidad.

En el caso del SAP, la SSF trata de persuadir a los empleadores morosos para que arreglen su situación con las AFP, antes de proceder a sancionarlos, de tal manera que una vez resuelta la condición de mora, podría atenuarse la sanción administrativa impuesta por la Superintendencia (multa). ${ }^{4}$

No obstante lo anterior, son pocos los grados de libertad con que cuenta la SSF para facilitar esta recuperación administrativa y las medidas conciliatorias que emprende son cuestionadas por algunos abogados, quienes sugieren que tal actuación excede las competencias de la referida entidad.

De igual manera, las gestoras de fondos privadas contactan a los empleadores morosos y procuran establecer con ellos acuerdos de pago de carácter unilateral para facilitar esa recuperación y legitimar el trámite de prestaciones iniciados por afiliados con cotizaciones en mora; esto quiere decir que, una persona que aparece en un acuerdo unilateral de pago suscrito por su empleador, puede tramitar, válidamente, una prestación dentro del sistema, aun cuando no estén acreditadas aún, todas sus aportaciones.

Las virtudes de este tipo de arreglo, sin embargo, entran en conflicto con la legalidad, ya que el empleador no le debe a la AFP, sino que a sus empleados (carga social) y los contratos de afiliación firmados entre el trabajador y las gestoras, no las faculta para negociar los términos de pago de las cotizaciones, pero sí para cobrar la mora que los afecta.

Esto originó, en el pasado, algunos señalamientos de parte de organizaciones laborales y de la sociedad civil que impidieron que esta cobranza sea más ágil; anteriormente, la figura que existía se denominaba compromiso de pago y se suscribían con las gestoras; pero, ante el temor de algún daño reputacional, estas últimas optaron por tramitar un formato distinto de compromiso unilateral, cuyo incumplimiento carece de consecuencias legales, lógicamente.

¿Por qué hemos puesto tanta atención a la cobranza de la mora previsional en este capítulo referido a la declaración y pago de las cotizaciones previsionales?

La respuesta a esta interrogante proviene del interés por destacar la irregularidad en

4 Aunque la norma no da opciones a la SSF para dispensar multas por mora previsional; debería pensarse en reformar la normativa para que sea posible, ya que la finalidad de la medida debería privilegiar el restablecimiento del saldo de la cuenta del afiliado, utilizando la sanción sólo para casos reiterativos de incumplimiento. 
el pago de estas obligaciones, en un primer momento, para luego dedicarnos al desarrollo de los aspectos centrales del pago normal de las cotizaciones.

Es más, una propuesta hecha en varias oportunidades al Ejecutivo, por el autor de este artículo ${ }^{5}$, a efecto de forzar a los empleadores a asumir una mayor responsabilidad en sus obligaciones con los trabajadores, fue hacer mucho más efectivo y explícito lo dispuesto en el artículo 50 de la Constitución de la República, en el sentido que la indemnización a los trabajadores y sus familias, relacionadas con la seguridad social fuera cubierta por los empleadores que no pagaren las cotizaciones oportunamente y que, como consecuencia de ello, los afiliados no pudieran reclamar los beneficios que le corresponden, por ministerio de ley, en las entidades gestoras donde se encuentren afiliados.

Esto último es el sentido práctico de la norma superior, en El Salvador; sin embargo, en ocasiones las autoridades sopesan demasiado el costo político de hacer valer los intereses de los trabajadores, incluyendo, en este caso, la responsabilidad laboral contemplada en la ley primaria de la República.

Además, debido a la naturaleza de la actividad regulada, el autor de este libro propuso también que se cambiara el tribunal competente para conocer este tipo de problemáticas, ya que por la forma en que se ha desarrollado la normativa previsional salvadoreña, se le ha dado un carácter mer- cantil, por excelencia, a la prestación del servicio, olvidándose en el camino de su esencia laboral.

A manera de ejercicio comparativo, vale la pena señalar que en el caso chileno estos juicios se administran en tribunales especiales, donde se privilegian los intereses de los trabajadores, a pesar que también le aplica un procedimiento parecido al caso salvadoreño, al recurrir a instancias penales en situaciones extremas; sin embargo, en Chile se tiene clara la finalidad de estas acciones; de igual forma se libran órdenes de captura y emiten restricciones migratorias para los empleadores morosos, como ha sucedido en algunas ocasiones en El Salvador; aunque esta medida sirve, principalmente, para que el empleador devuelva las cotizaciones retenidas a los trabajadores y que no fueron entregadas a las administradoras. ${ }^{6}$

Al cambiarse de tribunal, se esperaría que hubiera una mayor disposición de los jueces a actuar a favor de los trabajadores; no obstante, siempre sería necesaria una coordinación entre la SSF y estos tribunales para entender, apropiadamente, la naturaleza de los juicios y cuáles son los intereses que se están tutelando.

5 Cuando se desempeñó como Intendente del Sistema de Ahorro para Pensiones, de la extinta Superintendencia de Pensiones, entre los años de 1999 y 2011.

6 En el caso chileno las cotizaciones previsionales las pagan los trabajadores; mientras que el empleador sólo cubre el riesgo profesional, no así el común, el cual es cubierto a través de una póliza colectiva del ramo de personas, contratada por las administradoras en nombre de sus afiliados. 
Otra medida propuesta para disuadir la retención de cotizaciones a los trabajadores y su apropiación por parte de los empleadores, fue supeditar la renovación de la matrícula de comercio, a la comprobación de encontrarse solventes de las referidas obligaciones previsionales, tal como sucede, desde hace varios años atrás, con la participar en licitaciones públicas. Las empresas que deseen participar en concursos para la prestación de servicios a entidades gubernamentales o para suministrarles bienes, deben estar solventes con el pago de impuestos y cotizaciones previsionales.

Estas solvencias son emitidas por las gestoras de regímenes o fondos de pensiones, quienes verifican, en sus bases de datos, si las empresas se encuentran al día con el pago de sus obligaciones previsionales; aunque la forma en que se emiten podría mejorar, ya que se extienden solvencias ante la falta de información sobre adeudos por parte de las firmas. ${ }^{7}$

En más de alguna ocasión se discutió, inclusive, crear una lista de morosos previsionales, parecida a la publicada por los buró de crédito y que la condición de mora se considerara como un demérito para obtener préstamos del sistema bancario, porque al encontrarse en la lista sería un indicador de riesgo. Esta iniciativa tampoco prosperó.

En esta misma línea de acciones, cuando las empresas firman acuerdos unilaterales de pago, las gestoras les entregan constancias que están cumpliendo con el compromiso, pero dicho documento no es equivalente a la solvencia. Con su presentación no se puede participar en licitaciones públicas.

Ahora bien, el pago normal de las cotizaciones previsionales, en El Salvador, incluyen aportes de los trabajadores y sus empleadores, tanto en el caso del IPSFA, como en el caso del SAP. Las tasas de cotización difieren entre los esquemas administrados por las respectivas gestoras; en el caso del SAP, la cotización es del 6.25\% a cargo del trabajador y $6.75 \%$, para el empleador, para un total del 13\% del Salario Base de Cotización (SBC) ${ }^{8}$; mientras que en el IPSFA, son del $6 \%$ para el trabajador y $6 \%$, para el patrono; refiriéndonos aquí exclusivamente al régimen de pensiones.

No obstante lo anterior, el referido Instituto también administra otros programas con contribuciones adicionales de empleadores y trabajadores; en algunos de estos programas sólo se admite la afiliación de miembros de la Fuerza Armada; a continuación se presenta un cuadro detalle.

En tal sentido, las empresas morosas han decidido no presentar las declaraciones de pago, aunque no cancelen sus obligaciones de manera inmediata, porque con ello estarían reconociendo que no están solventes.

8 Dentro de esta cotización se incluye la comisión pagada a las AFP por la administración de las cuentas. 
Como puede apreciarse en el Cuadro 1, el IPSFA administra cuatro programas para el Régimen General, al cual pertenece el personal del Ministerio de la Defensa Nacional; pero además, hay diferentes poblaciones de afiliados bajo regímenes especiales que cotizan a varios de los programas señalados, salvo el del Fondo de Retiro, que es exclusivo del personal de alta, y que se hace efectivo -mediante un solo desembolso- cuando causan baja y han cumplido el tiempo necesario para acreditar el derecho, según la norma vigente.

\section{Cuadro 1: Porcentajes de cotizaciones y aportes de los regímenes del IPSFA - ley actual.}

\begin{tabular}{|c|c|c|c|c|c|c|c|c|c|c|c|c|c|c|c|c|}
\hline \multirow{3}{*}{ PRESTACIONES } & \multirow{2}{*}{\multicolumn{2}{|c|}{ RÉGIMEN GENERAL }} & \multicolumn{14}{|c|}{ REGGMENES ESPECIMES } \\
\hline & & & \multicolumn{2}{|c|}{ 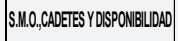 } & \multicolumn{2}{|c|}{ BOMBEROS } & \multicolumn{2}{|c|}{ PNC ATIIGUO } & \multicolumn{2}{|c|}{ CEAAFA } & \multicolumn{2}{|c|}{ AFILADO ART. 39 Y $4 \mathrm{C}$} & \multicolumn{2}{|c|}{ AFlLADO ART. 54} & \multicolumn{2}{|c|}{ EMPLEADOS PSSFA } \\
\hline & AFLLADO & APORTE & AFlLADO & APORTE & AFLLADO & APORTE & AFLLADO & APORTE & AFLLADO & APORTE & AFELLADO & APORTE & AFLLADO & APORTE & AFLLLADO & APORTE \\
\hline PENSIÓN & $6.0 \%$ & $6.0 \%$ & $6.0 \%$ & $6.0 \%$ & $6.0 \%$ & $6.0 \%$ & $6.0 \%$ & $6.0 \%$ & $6.0 \%$ & $6.0 \%$ & $6.0 \%$ & $6.0 \%$ & & & & \\
\hline REHABLLITACION & $1.0 \%$ & $1.0 \%$ & $1.0 \%$ & $1.0 \%$ & $1.0 \%$ & $1.0 \%$ & $1.0 \%$ & $1.0 \%$ & & & & & & & & \\
\hline SEGURO DE VIDA & $0.5 \%$ & $1.5 \%$ & $0.5 \%$ & $1.5 \%$ & $0.5 \%$ & $1.5 \%$ & $0.5 \%$ & $1.5 \%$ & $0.5 \%$ & $1.5 \%$ & & & $0.5 \%$ & $1.5 \%$ & $0.5 \%$ & $1.5 \%$ \\
\hline FONDO DE RETIRO & $3.0 \%$ & $3.0 \%$ & & & & & & & & & & & & & & \\
\hline SUB-TOTAL & $10.5 \%$ & $11.5 \%$ & $7.5 \%$ & $8.5 \%$ & $7.5 \%$ & $8.5 \%$ & $7.5 \%$ & $8.5 \%$ & $6.5 \%$ & $7.5 \%$ & $6.0 \%$ & $6.0 \%$ & $0.5 \%$ & $1.5 \%$ & $0.5 \%$ & $1.5 \%$ \\
\hline TOTAL DESCUENTOS & 2 & $\%$ & & $\%$ & 16 & $6 \%$ & & $6 \%$ & 14 & $4 \%$ & & $2 \%$ & & $2 \%$ & & $\%$ \\
\hline
\end{tabular}

Fuente: Elaborado por Haris Cerón, Jefe SAC del IPSFA.

Con la reforma a la Ley del IPSFA que se está discutiendo, las tasas de cotización se incrementarán hasta el 18\% para el Régimen de Pensiones, considerando que se implementará un Sistema de Capitalización Individual donde los beneficios se pagarán con los saldos acumulados por los trabajadores; en tal sentido, para asegurar una tasa de reemplazo superior a la esperada en el SAP -que rondaría el 35\% del Salario Básico Regulador (SBR)
9, la tasa de cotización total será, entonces, del 18\%, tal como aparece en el Cuadro 2. 
Cuadro 2: Tasas de cotizaciones y aportes capitalización individual.

\begin{tabular}{|c|c|c|c|}
\hline \multirow{2}{*}{ PRESTACIÓN } & \multicolumn{3}{|c|}{ REGIMÉN DE CAPITALIZACIÓN } \\
\hline & TRABAJADOR & EMPLEADOR & TOTAL \\
\hline PENSIÓN & $9.0 \%$ & $9.0 \%$ & $18.0 \%$ \\
\hline SEGURO DE VIDA & $0.5 \%$ & $0.5 \%$ & $1.0 \%$ \\
\hline FONDO DE RETIRO & $2.0 \%$ & $2.0 \%$ & $4.0 \%$ \\
\hline SEG. INVALIDEZ Y SOBREV. & $0.0 \%$ & $1.0 \%$ & $1.0 \%$ \\
\hline COMISIÓN ADMINISTRACIÓN & $1.0 \%$ & $1.0 \%$ & $2.0 \%$ \\
\hline TOTAL & $12.50 \%$ & $13.50 \%$ & $26.0 \%$ \\
\hline
\end{tabular}

Fuente: Elaborado por Carlos Zelaya, Jefe Depto. Contabilidad, IPSFA.

La reforma a la Ley del IPSFA contempla, de igual manera, que el Fondo de Retiro se administrará también bajo el esquema de capitalización individual, para lo cual se cotizará 4\% del SBC de los afiliados (2\% los trabajadores y $2 \%$ el patrono). ${ }^{10}$

En esta misma reforma, el programa de rehabilitación dejará de ser administrado por el IPSFA y será prestado por otra entidad relacionada con la Fuerza Armada. Esto puede apreciarse al comparar el Cuadro $1 \mathrm{y}$ 2 de este capítulo.

Por otro lado, en la actualidad, el NUP forma parte esencial de la información contenida en los expedientes de los trabajadores en todas las empresas. Este código se incorpora en la planilla de pago de cotizaciones para facilitar la identificación de los aportes.

Además, tanto en el caso del IPSFA como del SAP existen programas para generar planillas electrónicas que están disponibles en los sitios web de las instituciones gestoras; estas aplicaciones permiten importar la información necesaria desde las base de datos de los empleadores, facilitando con ello la elaboración de las planillas y reduciendo, a la vez, el riesgo de error humano.

Estos programas de computación han evolucionado con el tiempo, siendo la SSF la encargada de autorizar su uso en el país; de hecho la primera versión fue elaborada por la extinta Superintendencia de Pensiones. En el pasado reciente han convivido varias versiones de software para la generación de planillas, en el SAP, siendo la versión vigente, hasta el año 2014, el Sistema de Generación y Validación de Planillas Previsionales (SGVPP).

10 Esto resolvería de raíz el déficit del programa, ya que se manejaría con base a contribución definida y no, como beneficio definido. De ahí en adelante el afiliado recibiría el saldo de su cuenta de Fondo de Retiro cuando le dieran la baja. 
En estos momentos la SSF ha desarrollado una nueva versión para la elaboración de planillas en el SAP y en el Sistema de Pensiones Público (SPP), conformado por el Instituto Nacional de Pensiones de los Empleados Públicos (INPEP) y la Unidad de Pensiones del Instituto Salvadoreño del Seguro Social (UPISSS). Este sistema se denomina Sistema de Elaboración de Planillas Previsionales (SEPP). ${ }^{11}$

Dicho sistema es una aplicación web que, según la SSF, requiere pocos recursos tecnológicos, no demanda instalación previa y su actualización resulta simple y rápida. De igual manera, la Superintendencia señala que sólo es necesaria una conexión a Internet y que los usuarios se registren y definan sus roles en el sistema, al cual se puede accederse desde los sitios web de las AFP, el INPEP y la UPISSS.

El sistema es capaz de controlar el personal de una empresa por centros de trabajo, de costos u oficinas e inclusive, hacer una planilla consolidada, siendo compatible con diversos sistemas operativos y puede utilizar, de igual manera, varios navegadores, salvo con sistemas operativos anteriores a Windows 2000 .

Sin embargo, todavía existen versiones en papel donde se declaran cotizaciones previsionales y es numerosa la cantidad de planillas que se reciben así; pero en términos de recaudo, es menor a lo recibido a través de aplicaciones informáticas.

Gradualmente este tipo de obligaciones se cancelarán exclusivamente por medios electrónicos, tal como lo está impulsando el Instituto Salvadoreño del Seguro Social (ISSS), para el pago del régimen de salud y riesgo profesional.

En dicha Institución se está reemplazando el uso del papel para cobrar estas contribuciones; poco a poco se irán capitalizando los beneficios de estas modalidades de cobro.

La información relevante para el pago de las prestaciones se envía a través de planillas estándar, tal como se presenta a continuación, tanto para la realidad chilena, como para el caso del IPSFA y de las AFP. Ver Figuras 1, 2 y 3 .

11 En los sitios web de las AFP puede encontrarse el Manual de Usuario del referido sistema (Programa de Computación). 


\section{Figura 1}

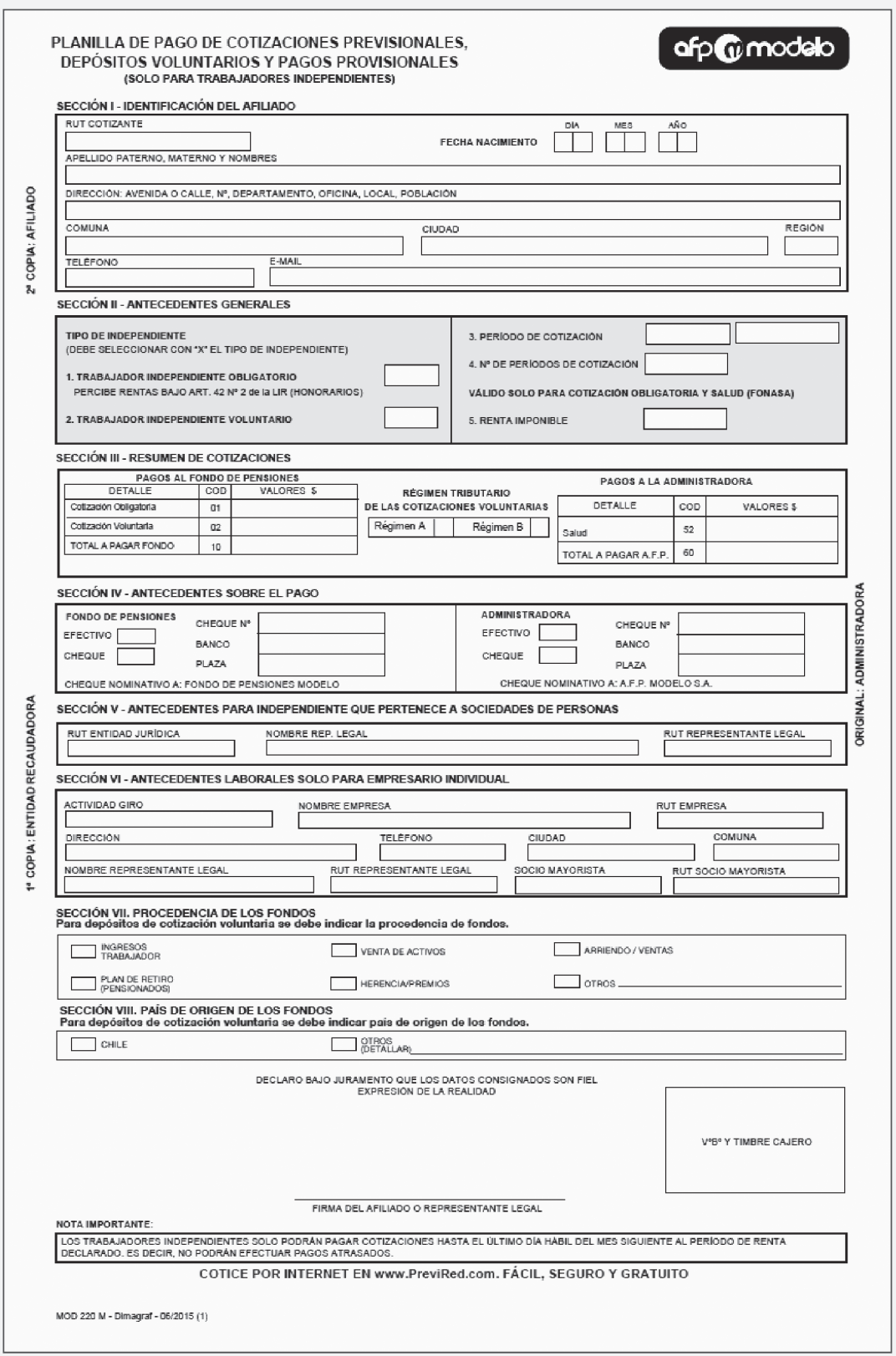

Fuente: Sitio Web AFP Modelo, Chile. 
En la Figura 1 se muestra el formato de declaración y pago para trabajadores independientes utilizado en Chile; tiene varios propósitos, ya que en dicho país los depósitos voluntarios pueden retirarse antes alcanzar la edad para jubilarse; mientras que en El Salvador este tipo de aportes forma parte del haber previsional para el pago de prestaciones.

Además, el valor cotizado por el afiliado sería idéntico al declarado si tuviera empleador, ya que en dicho país, el patrono no aporta al fondo de retiro de los trabajadores, como ya se mencionó antes.

\section{Figura 2}

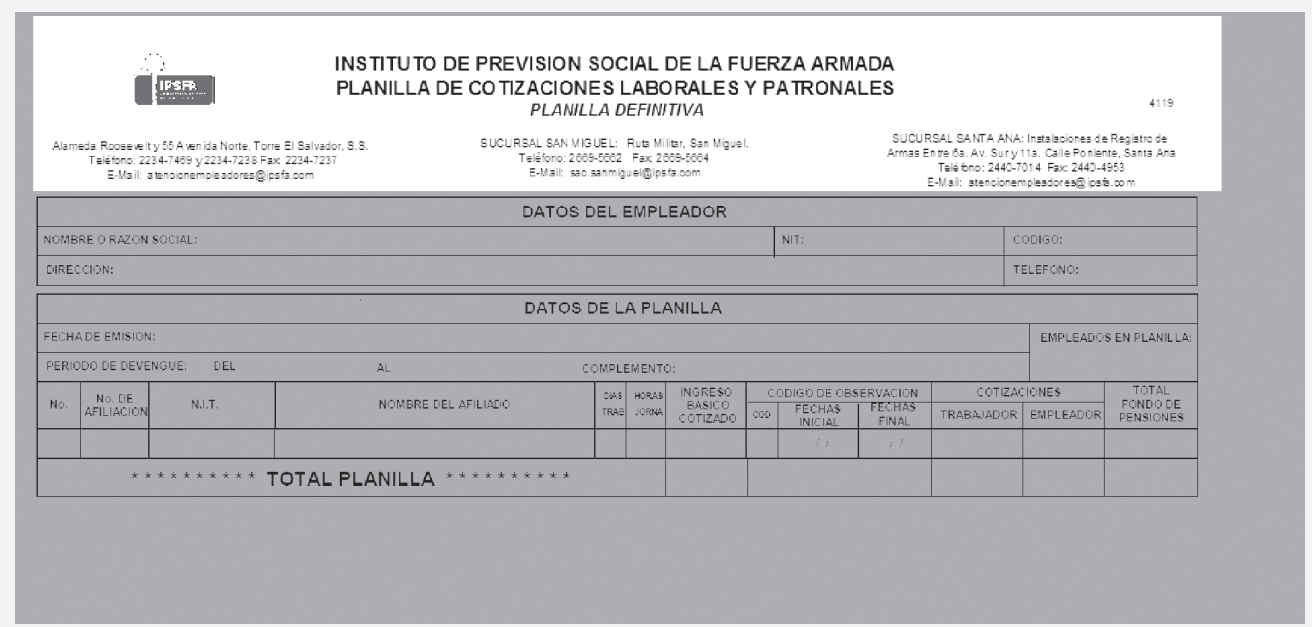

Fuente: Departamento de Afiliación del IPSFA

La planilla que aparece en la Figura 2 es la que está vigente, no la que se utilizará para la declaración y pago de cotizaciones previsionales para el Régimen de Pensiones y el de Fondo de Retiro, bajo la modalidad de cuenta individual.

Para efectos de control, en la planilla de cotizaciones previsionales -futuras-, se identificará al personal que continuarán aportando al régimen de reparto y quiénes lo harán a cuenta individual; de igual manera, será ne- cesario separar el importe destinado a pensiones (CIAP), así como el correspondiente al Fondo de Retiro (CIAFR).

Pero, a diferencia del SAP, en la planilla se agregará el pago por la administración de ambos regímenes; no se restará a las cotizaciones declaradas, por mes de devengue, como sucede en el SAP.

De igual manera se presenta, a manera de ilustración, un formulario de planilla de 
AFP Confía, que muestra la información básica que se debe enviar a la gestora de fondos para identificar a quién pertenecen los aportes y cualquier otra novedad necesaria para el control de las contribuciones de los afiliados. (Ver Figura 3)

Algunas de las novedades que se deben reportar en las planillas son las causales de haber dejado de pagar cotizaciones efectuadas en el pasado; será porque los trabajadores han renunciado, están incapacitados, fueron despedidos o están sancionados sin goce de sueldo, por ejemplo; caso contrario, los cambios en los valores declarados entre un mes y otro puede dar lugar a gestiones de cobro por parte de las administradoras, ante la presunción de mora. ${ }^{12}$

La recuperación de la mora presunta es de lo más complejo que existe en el SAP, ya que para lograrlo se requiere una depuración previa con el auxilio del empleador, quien debe justificar por qué no declaró determinadas cotizaciones, por mes de devengue ${ }^{13}$; se corrigen así los registros para precisar cuánto es lo adeudado y los intereses dejados de percibir por los afectados (afiliados).

\section{Figura 3}

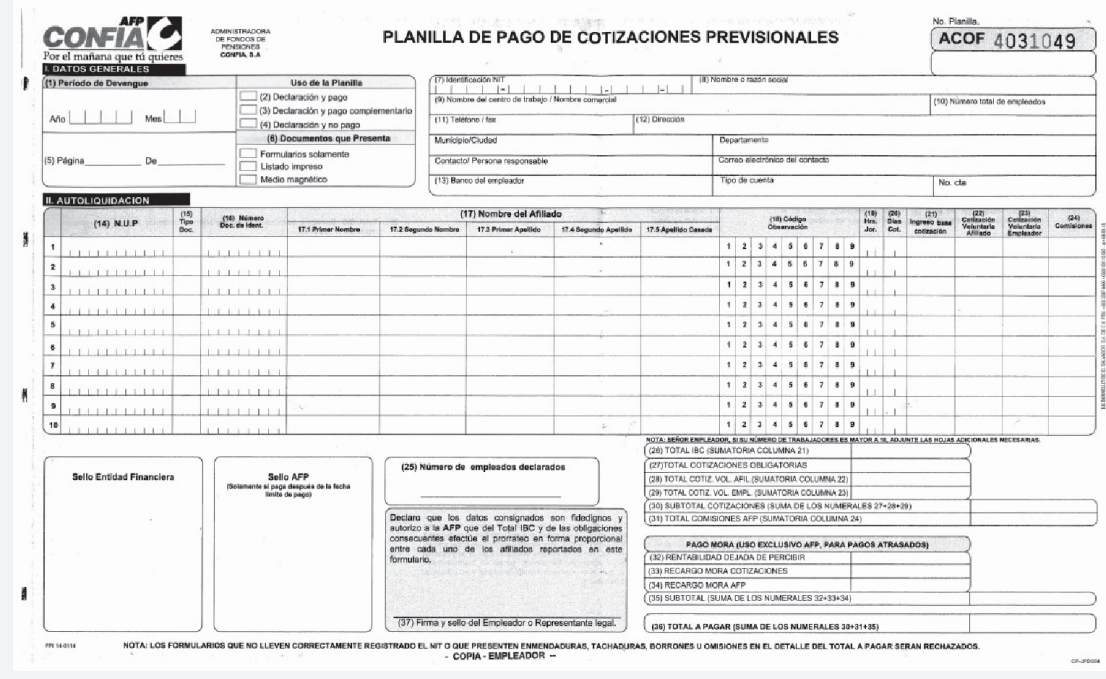

Fuente: AFP CONFIA

12 En el SAP se maneja la figura de mora presunta, la cual se origina por la falta de declaraciones de cotizaciones de trabajadores reportadas en fechas anteriores, algunas de sus causas son abandonos de los centros de trabajo por parte de los afiliados, que no son señalados en los códigos de observación de las planillas previsionales 0, inclusive, por descoordinaciones temporales entre las AFP, por los traspasos autorizados entre una fecha de devengue salarial y otra.

13 El mes de devengue o devengue, a secas, se refiere al mes en que el trabajador devengó el salario y por ende, también acreditó el derecho al resto de accesorios, como son, entre otros derechos, el de la seguridad social (cotizaciones y aportes previsionales). 
Como puede apreciarse en la Figura 3, el documento incluye, además de las generales del empleador; el NUP; un espacio para el DUI, el nombre completo del trabajador ${ }^{14}$; un campo de códigos de observación, por afiliado, donde se señalan las novedades típicas que explicarían el pago de valores inferiores a los esperados o el cambio en el número de trabajadores declarados de un mes a otro; el IBC de los trabajadores; así como las cotizaciones adicionales efectuadas, a título voluntario, a favor de los afiliados.

Cuando las declaraciones son físicas, deben lotearse (agrupar en lotes de planillas para luego digitarlas, principalmente para el caso de las versiones físicas) para procesarlas; con ello se facilita la trazabilidad futura de las planillas y registros, en caso de errores de acreditación; mientras que las electrónicas se cargan directamente a las bases de datos, a través de los sistemas de acreditación.

Estos procesos de acreditación se programan con anticipación, dado que durante éstos se demanda mucha capacidad de memoria de los sistemas, lo cual reduce los tiempos de respuesta de otras aplicaciones utilizadas simultáneamente por las gestoras.

\section{Conclusiones}

Los sistemas de pensiones contributivos dependen de los aportes de sus afiliados para financiarse, tanto aquellos basados en regímenes de reparto como de capitalización individual.

La forma, montos y periodicidad en que se efectúan las contribuciones están regulados por el Estado y el incumplimiento de las normas emitidas, para tales efectos, conduce a sanciones de carácter pecuniario y, en algunos casos, son hasta de índole penal, como sucede en el país, al amparo del artículo 245 del Código Penal.

Sin embargo, la principal sanción para los morosos debería consistir en trasladarle la responsabilidad del pago de los beneficios indemnizatorios, para sus trabajadores y resto de familiares, cuando por el incumplimiento de sus compromisos, los afiliados pudieran quedar descubiertos de la red de protección social organizada por el Estado, tal como lo ordena la Constitución de la República de El Salvador en sus artículos 50, 51 y 52 .

En todo caso, el fin último de las medidas punitivas contenidas en las normas aplicables al incumplimiento del pago de las cotizaciones previsionales debería ser el restablecimiento de las condiciones que tendrían las cuentas de los trabajadores, si el empleador no estuviera en mora.

En aras de lograrlo, el autor de este artículo propuso al Ejecutivo, en su oportunidad, una serie de medidas disuasivas de estas prácticas empresariales que podrían ser retomadas por los rectores de la industria, más adelante, para privilegiar los intereses de los trabajadores por encima de todo.

14 Originalmente la planilla no incluía el nombre, lo cual generó enormes problemas de rezago, ya que la digitación manual no contaba con otros datos para validar el registro, ni para identificar errores de digitación. 


\section{Bibliografía}

1 AFP CONFIA; Sistema Elaboración de Planillas Previsionales "SEPP", Manual del Usuario; San Salvador 2015.

2 ASAMBLEA LEGISLATIVA; Ley Orgánica de la Superintendencia de Pensiones; Decreto 926; San Salvador 1996.

3 ASAMBLEA LEGISLATIVA; Ley del Sistema de Ahorro para Pensiones; Decreto 927; San Salvador 1996.
4 INSTITUTO DE PREVISIÓN SOCIAL DE LA FUERZA ARMADA; Propuesta de reforma a la Ley de IPSFA; San Salvador 2011.

5 ÓRGANO EJECUTIVO; Reglamento de Recaudación de Cotizaciones al Sistema de Ahorro para Pensiones; Decreto 28; San Salvador 2006

6 SORTO RIVAS, Francisco; RENTAS VITALICIAS VINCULADAS A SISTEMAS DE CAPITALIZACIÓN INDIVIDUAL DE PENSIONES, ISEADE, EI Salvador 2015. 